\section{Abortion: Humanized Attention and Legal Aspects}

\title{
Aborto: atenção humanizada e aspectos legais
}

RESUMO | Introdução: O abortamento é definido como a interrupção gestacional até a $20^{\mathrm{a}} / 22^{\mathrm{a}}$ semana e com o concepto pesando menos que $500 \mathrm{~g}$. Objetivo: Tratase de estudo teórico em que se pretendeu analisar o abortamento e suas práticas lícitas e ilícitas sob a ótica do Princípio Fundamental da Dignidade Humana, em sua perspectiva constitucional, tendo em vista, ainda, suas considerações éticas, normativas penais e deontológicas, estas últimas conforme a codificação profissional da medicina no Brasil. Métodos: Para contextualização da problemática, partiu-se da apresentação de dados colhidos em estudos estatísticos prévios, trabalhandose, em seguida, com a análise teórica dos impactos negativos da criminalização do aborto no Brasil diante de problemas de ordem socioeconômica verificados. Resultados: Os aspectos religiosos e a liberdade fundamental também restaram elencados nos argumentos refletidos no texto, apresentando vieses de argumentos favoráveis e contrários à realização do ato, incluindo-se o instituto da objeção de consciência e seus possíveis limites. Conclusão: Alcança-se, por fim, a ratificação do devido respeito à dignidade humana reforçando-se a manutenção do respeito ao direito à saúde independentemente à natureza do ato enquanto conforme ou não ao quanto disposto pela norma brasileira, na atualidade.

Palavras-chave| Aborto; Direitos humanos; Humanização da assistência.

${ }^{1}$ Faculdade de medicina da Bahia, Universidade Federal da Bahia. Salvador/BA, Brasil.

${ }^{2}$ Programa de Pós-Graduação em Direito, Governança e Políticas Públicas, Universidade Salvador. Salvador/BA, Brasil. 


\section{INTRODUÇÃO|}

O abortamento é definido como a interrupção gestacional até a $20^{\mathrm{a}} / 22^{\mathrm{a}}$ semana e com o concepto pesando menos que $500 \mathrm{~g}^{1}$. O abortamento pode ser espontâneo, quando a interrupção ocorre de forma natural, condicionada por questões orgânicas e de saúde materna, ou artificial, quando essa prática é realizada por induzimento, seja através de conduta promovida pela gestante ou por outra pessoa, incluindo-se profissionais de saúde após a obtenção do seu consentimento.

Em 2008, nos países em desenvolvimento, ocorreram 3,78 abortos induzidos em cada 100 mulheres na faixa etária de 15 a 44 anos $^{2}$. Desse total, 56\% foram feitos de forma insegura, colocando a saúde e a própria vida da gestante em risco. No Brasil ${ }^{3}$, entre 1992 e 2005, houve redução no número de internações por abortamento registradas pelo SUS, na faixa etária de 15 a 49 anos. A estimativa de abortos inseguros na mesma faixa etária também reduziu, assim como as taxas anuais de abortos inseguros (de 3,69 para 2,07 a cada 100 mulheres). O risco de abortos inseguros nas Regiões Nordeste e Centro-Oeste foi duas vezes maior que na Região Sul, sendo que a população de mulheres negras apresentou coeficiente de mortalidade, em consequência de abortamento inseguro, três vezes maior que o das mulheres brancas. Segundo o mesmo estudo ${ }^{3}$, a cobertura insuficiente de medidas anticoncepcionais pode resultar em gestações não planejadas, ocasionando abortamento inseguro em mais de um milhão de mulheres por ano, podendo ocorrer complicações graves como hemorragias, infecções, perfuração uterina, esterilidade e óbito materno.

Portanto, o abortamento representa um problema de saúde pública no Brasil, e a criminalização do ato deve ser discutida pela sociedade, pois dificulta o conhecimento do problema, assim como aumenta os riscos do abortamento inseguro. As populações mais vulneráveis socioeconomicamente são penalizadas pelo estigma e preconceito social. É necessário que o Estado promova ações efetivas de conscientização, empoderando as populações mais vulneráveis sobre seus direitos.

A realização do abortamento ainda é crime tipificado no Código Penal brasileiro ${ }^{4}$. O Sistema Normativo no Brasil busca impedir a prática, cominando pena específica para quem pratica, embora dados brasileiros evidenciem que a criminalização do ato não reduz a sua incidência ${ }^{3}$. A lei, porém, permite a prática em casos extremos que serão descritos na abordagem jurídica do presente texto.

O abortamento também não é permitido pelas doutrinas religiosas predominantes no país. Os fiéis subordinados ao pensamento religioso são impedidos dessa prática, e, quando a praticam, sofrem, na maioria das vezes, com a discriminação e o preconceito. Assim, o abortamento é também uma problemática religiosa.

Todos esses fatores contribuem para a possibilidade de ocorrência de um preconceito também por parte do corpo médico, quando na prática do abortamento previsto por lei ou na atenção humanizada aos casos sob sua responsabilidade. Mesmo que a conduta vá de encontro ao pensamento religioso, ou ainda que a conduta seja ainda posta enquanto ilícita, as gestantes devem receber tratamento ao nível do Princípio Fundamental Brasileiro da Dignidade da Pessoa Humana 5 .

O objetivo deste estudo foi analisar o abortamento sob a ótica do Princípio Constitucional da Dignidade da Pessoa Humana, tendo em vista, ainda, suas considerações éticas, penais e deontológicas, esta última de acordo com a codificação profissional da medicina no Brasil.

\section{MÉTODOS|}

Para contextualização da problemática, apresentaramse dados colhidos em estudos estatísticos prévios, trabalhando-se, posteriormente, com a análise teórica dos impactos negativos da criminalização do aborto no Brasil diante de problemas de ordem socioeconômica verificados, discutindo-se o aborto como uma questão de saúde pública, como uma questão religiosa e como uma questão jurídica.

Trata-se de uma pesquisa teórica, que utilizou tanto o método de raciocínio indutivo, quanto o dedutivo, tendo em vista que partiu de dados concretos empíricos para a construção de determinadas assertivas e, posteriormente, realizouse um estudo dedutivo, verificando-se as normativas do ordenamento jurídico brasileiro, com a aplicação no caso concreto específico da prática do abortamento.

A linha deste trabalho é a da tecnologia social científica ${ }^{6}$, tendo em vista que se utiliza do pensamento jurídico como uma tecnologia voltada para questões sociais. A 
vertente da pesquisa é a jurídico-sociológica, investigando a relação entre as disposições jurídicas, sociais e políticas ${ }^{6}$. Foram utilizados dados primários, como legislação e a doutrina jurídica.

\section{RESULTADOS/DISCUSSÃO|}

Identificaram-se neste estudo teórico quatro temáticas a serem apresentadas e discutidas a seguir: abortamento como uma questão de saúde pública, abortamento como uma questão jurídica, abortamento como uma questão religiosa e abortamento à luz do princípio constitucional da dignidade da pessoa humana.

O abortamento é uma questão de saúde pública que necessita ampla discussão pela sociedade brasileira, pois representa importante causa de mortalidade materna no Brasil. A complexa temática do abortamento, aliada aos aspectos legais envolvidos, dificulta uma estimativa de sua gravidade, no contexto cultural brasileiro. Apesar dos poucos estudos empíricos sobre o abortamento, as pesquisas brasileiras têm indicado que a prática do abortamento não é inibida pelo fato de o procedimento ser ilegal e que a sua incidência está relacionada às desigualdades sociais. Uma faceta dessa desigualdade emerge quando se constata que a grande maioria dos casos notificados se refere a mulheres pobres, sem acesso a recursos que possibilitem um abortamento seguro ${ }^{7}$.

Em 20107,8, uma pesquisa de abrangência nacional com 2002 mulheres alfabetizadas que abortaram revelou que o abortamento foi mais frequente na faixa etária de 25 a 29 anos, em mulheres de menor escolaridade; a religião não foi fator decisivo para prática do ato, não havendo diferença significante entre elas (Tabela 1).
Uma análise sobre 20 anos de pesquisas realizadas na temática do abortamento no Brasil $^{7}$ revelou que a criminalização do ato, além de não coibir a prática, traz consequências negativas para a saúde das mulheres. Importante ressaltar que os riscos do abortamento inseguro foram majoritariamente vividos por mulheres pobres e sem acesso a recursos médicos para uma prática segura. Além disso, destaque-se que as mulheres que buscaram o serviço público para atenção à saúde em caso de abortamento eram na grande maioria, além de economicamente desfavorecidas, jovens católicas e já com filhos ${ }^{7,8}$.

No Brasil, dados do DATASUS ${ }^{9}$ para o período de 1996 a 2016 revelam a ocorrência de 1755 óbitos maternos consequentes ao abortamento, sendo 61\% dos abortamentos de causa não esclarecida (Tabela 2).

Tabela 2 - Número de óbitos maternos relacionados ao abortamento, Brasil, 1996 a 2016

\begin{tabular}{lcc}
\hline Causas de abortamento & N & $\%$ \\
\hline Abortamento espontâneo & 212 & 12,1 \\
Abortamento por razões médica & 11 & 0,6 \\
Outros tipos de abortamento & 252 & 14,4 \\
Abortamento não esclarecido & 1071 & 61,0 \\
Falha na tentativa de abortamento & 209 & 11,9 \\
\hline Total & $\mathbf{1 . 7 5 5}$ & $\mathbf{1 0 0}$ \\
\hline
\end{tabular}

Fonte: DATASUS 9 .

Utilizando-se a mesma base de dados, ${ }^{9}$ observou-se que dentre os 1755 casos de óbito consequentes ao abortamento, 50,6\% correspondiam a mulheres negras/ pardas, na faixa etária entre 20-29 anos (47,3\%), solteiras $(63,6 \%)$, com escolaridade menor que sete anos $(35,5)$ ou

Tabela 1- Prática do abortamento segundo a religião. Pesquisa Nacional de Aborto, 2010

\begin{tabular}{|c|c|c|c|c|}
\hline \multirow{2}{*}{ Religião } & \multicolumn{4}{|c|}{ Você já fez aborto alguma vez? } \\
\hline & Não & Sim & $\%$ & (IC95\%) \\
\hline Católica & 1168 & 175 & 15,0 & 2,0 \\
\hline Evangélica ou protestante & 551 & 72 & 13,0 & 1,0 \\
\hline Outras religiões & 81 & 13 & 16,0 & 2,0 \\
\hline Não tem religião ou não respondeu & 202 & 36 & 18,0 & 2,0 \\
\hline
\end{tabular}

Fonte: Diniz e Medeiros ${ }^{7}$, modificado. 
ignorada $(38,2)$. Os óbitos foram na grande maioria durante o abortamento $(44,8 \%)$ ou período ignorados $(39,4)$ e em ambiente hospitalar (93,1\%). Esses dados, embora não estimem fielmente a problemática no Brasil, possibilitam um desenho do quadro em consonância com estudos prévios: o abortamento notificado no Brasil incide em mulheres em estado de vulnerabilidade econômica, social e com autonomia reduzida.

Em 2012, um estudo qualitativo foi realizado com mulheres hospitalizadas por abortamento em uma Maternidade Pública de Salvador, Bahia ${ }^{10}$. Esse estudo procurou identificar situações que interferiram na decisão pela prática do abortamento e os sentimentos envolvidos no processo. A amostra foi constituída por mulheres negras, casadas ou com união estável, dependentes financeiramente do companheiro. Dificuldade financeira, o número de filhos, violência conjugal e perda de autonomia foram identificados como os principais motivos que levaram à prática do abortamento. O processo entre a descoberta e a decisão de interrupção da gravidez foi relatado como doloroso, com sentimentos de medo, tristeza, angústia, culpa e alívio durante sua ocorrência. $\mathrm{Na}$ ausência de ajuda efetiva, as mulheres relataram persistência de dor e sentimento de culpa ${ }^{10}$.

Em 2005, o Ministério da Saúde elaborou Normas Técnicas para atendimento ao abortamento resultante de violência sexual ${ }^{11}$, considerando que o Código Penal Brasileiro $^{4}$ (CPB) não exige documentação específica para prática do abortamento nesses casos. Portanto, mesmo que a mulher opte por não notificar o fato à polícia, o direito do abortamento não lhe pode ser negado. Os profissionais de saúde estão igualmente resguardados pelo $\mathrm{CPB}$ (art. 20, $\int 1^{\circ}$ ) que garante isenção de pena a quem, por erro plenamente justificado pelas circunstâncias, supõe situação de fato que, se existisse, tornaria a ação legítima. Nesse caso, havendo alegação da gestante de gravidez por violência, é necessário que o médico parta do pressuposto da veracidade dos fatos. No caso em particular, é permitido ao médico alegar objeção de consciência, caso haja outro profissional que possa realizar o ato ${ }^{12}$.

A não realização do procedimento, na ausência de alguém que possa executá-lo, pode acarretar danos à mulher, indo de encontro ao dever do médico de agir com prudência, diligência e perícia. O Código de Ética Médica $^{12}$, em seu artigo Primeiro, seguido pelo Parágrafo Único, veda ao médico causar dano ao paciente por ação
Tabela 3 - Características sociodemográficas dos 1755 óbitos maternos consequentes a abortamento. Brasil, 2011

\begin{tabular}{|c|c|c|}
\hline Características sociodemográficas & $\mathbf{N}$ & $\%$ \\
\hline \multicolumn{3}{|l|}{ Raça } \\
\hline Branca & 553 & 30,5 \\
\hline Preta/pardo & 887 & 50,6 \\
\hline Outros & 21 & 1,2 \\
\hline Ignorados & 294 & 16,7 \\
\hline \multicolumn{3}{|l|}{ Idade (anos) } \\
\hline $10-14$ & 24 & 1,4 \\
\hline $15-19$ & 268 & 15,3 \\
\hline $20-29$ & 831 & 47,3 \\
\hline $30-39$ & 545 & 31,0 \\
\hline $40-49$ & 87 & 5,0 \\
\hline \multicolumn{3}{|l|}{ Estado Civil } \\
\hline Solteiro & 1116 & 63,6 \\
\hline Casado & 356 & 20,3 \\
\hline Separado Judicialmente & 43 & 2,4 \\
\hline Viúvo/Outro & 100 & 5,7 \\
\hline Ignorado & 140 & 8,0 \\
\hline \multicolumn{3}{|l|}{ Escolaridade (anos) } \\
\hline 0 a 7 & 622 & 35,5 \\
\hline 8 a 11 & 377 & 21,5 \\
\hline 12 e mais & 85 & 4,8 \\
\hline Ignorado & 671 & 38,2 \\
\hline \multicolumn{3}{|l|}{ Período } \\
\hline Durante gravidez, parto ou abortamento & 786 & 44,8 \\
\hline Durante o puerpério & 277 & 15,8 \\
\hline Ignorado/n informado & 692 & 39,4 \\
\hline \multicolumn{3}{|l|}{ Local } \\
\hline Hospital/estabelecimento saúde & 1634 & 93,1 \\
\hline Domicílio & 57 & 3,2 \\
\hline Via pública & 24 & 1,4 \\
\hline Outros/lgnorado & 40 & 2,3 \\
\hline
\end{tabular}

Fonte: DATASUS ${ }^{9}$. 
ou omissão, caracterizada como imperícia, imprudência ou negligência, sendo a responsabilidade médica pessoal e não presumida. Nos casos de negligência ou omissão, o profissional da medicina pode ser responsabilizado, ética, civil e criminalmente, pelos agravos físicos e mentais que a gestante possa sofrer ${ }^{4,12}$. No que concerne ao Estado, o direito à saúde está associado ao direito à vida. A Constituição Federal $^{5}$ dispõe que a saúde é um direito de todos e dever do Estado, garantido por meio de políticas públicas que objetivam prevenção, redução de riscos e outros agravos, sendo o acesso universal e igualitário ${ }^{13}$. Dessa forma, é dever do Estado prover profissionais que realizem o abortamento nos hospitais públicos.

No abortamento, tutela-se a vida intrauterina que se inicia, juridicamente falando, com a nidação até o início do parto que se configura com a incisão - em caso de parto cesáreo - ou dilatação - em caso de parto normal. A conduta abortiva é um crime tipificado nos artigos 124 a 128 do Código Penal ${ }^{4}$. A lei, com o dispositivo, objetiva a tutela da vida humana em desenvolvimento e é taxativa ao cominar uma pena aos praticantes do delito. Sendo assim, não realiza qualquer análise sob o ponto de vista das questões sociais e de gênero, não cuidando, especificamente da vulnerabilidade da mulher ou precariedade de suas condições de vida.

Saliente-se que a doutrina estabelece a existência de duas espécies de aborto, quais sejam, o aborto natural ou espontâneo e o aborto provocado, e este último poderá ser realizado na forma dolosa - quando há a intencionalidade da realização da prática - ou culposa - quando não há a intencionalidade, mas há a assunção do risco ${ }^{14}$. No que se refere à aplicação da Lei penal, é necessário esclarecer que ao aborto natural ou espontâneo não deve ser imputado qualquer pena, tendo em vista que, naturalmente, o próprio organismo da gestante, impede a continuação da gravidez. Entretanto, o aborto provocado é de extrema importância para a aplicação da Lei penal, tendo em vista que a sua prática dolosa é tipificada como crime nos artigos 124 a 128 do Código Penal ${ }^{4}$.

O artigo 124 imputa o crime de aborto à gestante, que poderá incorrer na prática em duas hipóteses, quais sejam, provocar aborto em si mesma (autoaborto) ou consentir que outra pessoa provoque a prática abortiva, cominando, como pena, a de detenção, de um a três anos.
Os artigos 125 e 126 do Código Penal ${ }^{4}$ trazem a modalidade de aborto provocado por terceiro, sendo que o primeiro, tipifica como crime a conduta de provocar o aborto sem o consentimento da gestante, e o segundo estabelece como criminosa a conduta de provocar o aborto com o consentimento da gestante. Verifica-se, ademais, uma diferença significativa quando comparadas as penas cominadas para cada delito, tendo em vista que, enquanto no delito tipificado no artigo 125 a pena é de reclusão de três a dez anos, o artigo 126 estabelece como pena também a reclusão, no entanto esta que deverá ser cumprida de um a quatro anos. Saliente-se que o parágrafo único do artigo 126 estabelece casos taxativos em que a pena cominada deverá ser a pena prevista no artigo 125 , devendo-se aplicar a pena mais gravosa se a gestante não for maior de quatorze anos, ou for "alienada ou débil mental, ou se o consentimento é obtido mediante fraude, grave ameaça ou violência"4.

$\mathrm{O}$ artigo 127 estabelece causas de aumento de pena em um terço se, em consequência da prática abortiva ou dos meios empregados para provocá-la, a gestante sofrer lesão corporal de natureza grave. Ademais, o mesmo dispositivo estabelece que as penas cominadas deverão ser duplicadas caso haja, em consequência dessas causas, a morte da gestante ${ }^{4}$.

O Código de Ética Médica ${ }^{12}$, em seu artigo 43, também veda ao médico o descumprimento de legislação específica nos casos de abortamento. O mesmo diploma normativo possibilita a prática do abortamento estritamente em dois casos: no abortamento terapêutico e no abortamento humanitário, como prevê o art. 128 do Código Penal ${ }^{4}$. O abortamento terapêutico, necessário ou profilático ocorre quando não há outro meio para salvar a vida da gestante. Já o abortamento humanitário, ético ou sentimental ocorre nos casos em que a gestante foi vítima de estupro. A permissão legal ao ato toma como base aspectos éticos e humanitários e, embora o caput do artigo expresse que não se pune abortamento praticado por médico nesses dois casos, a interpretação deve ser feita ampliativamente.

Além das possibilidades de abortamento permitidas por Lei, o Supremo Tribunal Federal julgou a Arguição de Descumprimento de Preceito Fundamental de $\mathrm{n}^{\circ}$ 54, diante da situação de abortamento de um feto anencefálico, ou seja, que possuía uma má formação que apresenta remanescentes do tronco encefálico que torna a vida pós-uterina inviável. Não há previsão legal específica 
que regulamente o referido caso concreto, tendo sido, deste modo, decidido que a dignidade da gestante deveria prevalecer em detrimento à vida (sobrevida) do feto ou neonato. Concebeu-se, desta forma, a antecipação da morte do feto ${ }^{14}$. O anteprojeto da reforma do Código Penal já revoluciona a temática, trazendo o abortamento nesses casos como um fato não punível.

Existem defensores da incriminação do abortamento e aqueles que buscam a supressão da incriminação da prática abortiva. A corrente que defende a legalização argumenta que mesmo que a lei penal proíba o ato, a realização de abortamentos é frequente. Em clínicas clandestinas, que não possuem ambiente e técnicas adequadas, a vida da gestante é colocada em risco. Por outro lado, existem os que defendem sempre o prevalecimento da vida, especialmente a que está em formação ${ }^{14}$.

O grande objetivo da legislação é tutelar assim o bem jurídico da vida em desenvolvimento. Há, em questão, um conflito entre direitos individuais previstos no art. $5^{\circ} \mathrm{da}$ Constituição Federal ${ }^{5}$. O direito à vida se confronta com o direito à liberdade. $\mathrm{O}$ direito à liberdade dá poder de autodeterminação ao ser humano, que direciona livremente o indivíduo para a sua felicidade. Porém, o direito à vida ainda é o bem jurídico preponderante no conflito. A vida, enquanto bem jurídico mais importante ao ordenamento jurídico, possui maior tutela. Assim, mesmo limitando a liberdade, a proibição do abortamento apresenta-se como garantia do respeito ao direito à vida. Não há, contudo, percepção normativa no âmbito penal para a problemática dos óbitos maternos ocorridos, tendo em vista a manutenção da criminalização do aborto, o que pode apresentar-se como um contrassenso.

Apesar de o abortamento ser crime no Brasil, em caso de ocorrência do ato, independentemente de sua natureza, ao profissional de saúde não é permitida a quebra do sigilo. O paciente tem o direito civil e constitucional do respeito à sua autonomia, que inclui o sigilo e privacidade. Os profissionais de saúde não podem informar a ocorrência específica do abortamento à autoridade policial, judicial ou Ministério Público, pois o exercício das profissões de saúde alicerça-se em uma relação de confiança e fidelidade.

Neste sentido, importante ressaltar que, mesmo havendo eventual desconfiança de uma dessas instituições no que tange à ocorrência de aborto, o Código de Ética Médica proíbe o médico de qualquer entrega de informação que acarrete em demanda judicial contra a paciente. É o que traz o art. 73, Parágrafo Único, alínea c: "na investigação de suspeita de crime, o médico estará impedido de revelar segredo que possa expor o paciente a processo penal."

Além disso, a quebra de sigilo e privacidade pode ocasionar processo ético, civil e criminal contra o profissional de saúde. O Código Penal Brasileiro (art. 154) ${ }^{4}$ caracteriza como crime o ato de revelar a alguém, sem justa causa, segredo de que tem ciência em razão de exercício profissional. Em consonância com a legislação brasileira, o Código de Ética Médica ${ }^{12}$ (art. 73) veda ao médico a revelação de fato de que tenha conhecimento em virtude do exercício de sua profissão, salvo por motivo justo, dever legal ou consentimento, por escrito, do paciente.

O direito ao sigilo também é estendido aos menores de idade, tal como também dispõe o Código de Ética Médica ${ }^{12}$, em seu art. 74, em que consta ser vedado ao médico revelar segredo profissional referente aos mesmos, inclusive a seus pais ou responsáveis legais. Contudo, essa manutenção do sigilo deve ser observada desde que o adolescente tenha capacidade de avaliar seu problema, e não deve ser cumprida quando, ausente a capacidade de discernimento, ou a não revelação possa acarretar danos.

A Constituição Brasileira ${ }^{5}$ assegura a liberdade de consciência e crença. A liberdade de consciência não se relaciona diretamente com a liberdade de crença. Trata-se de dois conceitos distintos. Por exemplo, a liberdade de consciência pode caminhar no sentido agnóstico, assim como pode adotar valores morais e espirituais que não se fundamentam em religião específica. A Carta Magna brasileira assegura o respeito à liberdade religiosa, havendo separação entre Estado e Igreja; no entanto, estabelece uma cooperação entre ambos ${ }^{13}$.

A religião predominante no Brasil, o Cristianismo, possui concepção fundamentada na hermenêutica da Bíblia Sagrada, que é a sua fonte doutrinária. Segundo a interpretação da Igreja, a vida tem um significado religioso desde antes da fecundação. Essa fundamentação é descrita pelo jurista Rogério Greco ${ }^{14}$ por meio de algumas passagens bíblicas. Uma delas se encontra no livro de Jeremias Capítulo I, versículos 5 e 6 que versa sobre a constituição de Jeremias como profeta antes mesmo de ele ter sido formado no ventre materno. Outra passagem de abordagem semelhante se refere ao salmista Davi no livro de Salmos, Capítulo 139 Versículo 16. Para o referido 
jurista, embora os seres humanos não tenham consciência, existe um propósito superior determinado por Deus e, a não ser por situações excepcionais, não se pode tirar a vida de semelhante, não importando o seu tamanho ${ }^{14}$.

É importante salientar, nesse contexto, que a revelação Divina é personalíssima e não deve ser aplicada para todas as pessoas como uma regra comum. Além disso, interpretações estreitas das Escrituras podem levar ao contraditório dos fundamentos basilares cristãos: amor e misericórdia. Assim, é certo que cada indivíduo deve ser respeitado em sua crença, sendo esse um direito constitucional. Dessa forma, a objeção de consciência é um direito fundamental, representando o eixo básico de onde emana a liberdade de pensamento. No entanto, questiona-se a licitude dessa reivindicação quando existem riscos de danos físicos, psicológicos e morais às mulheres em processo de abortamento.

Neste sentido, vale citar o item VII do Capítulo 1 do Código de Ética Médica ${ }^{12}$, que possibilita, claramente, a prática da objeção de consciência, ressalvados os casos de ausência de outro médico que realize o ato, de situações de urgência ou emergência, ou quando a recusa possa ocasionar danos à saúde do paciente:

VII - O médico exercerá sua profissão com autonomia, não sendo obrigado a prestar serviços que contrariem os ditames de sua consciência ou a quem não deseje, excetuadas as situações de ausência de outro médico, em caso de urgência ou emergência, ou quando sua recusa possa traz̧er danos à saúde do paciente ${ }^{12}$.

O item IX do Capítulo II do Código de Ética Médica ${ }^{12}$ ratifica a objeção de consciência ao estabelecer, como direito do médico "recusar-se a realizar atos médicos que, embora permitidos por lei, sejam contrários aos ditames de sua consciência"12.

É necessário salientar, todavia, que a objeção de consciência não é absoluta, havendo situações em que a recusa não é permitida. Neste sentido, a norma técnica do Ministério da Saúde $^{11}$ estabelece três hipóteses que impedem a objeção de consciência do Médico, quais sejam:

a) em caso de necessidade de abortamento por risco de vida para a mulher;

b) em qualquer situação de abortamento juridicamente permitido, na ausência de outro(a) médico(a) que o faça e quando a mulher puder sofrer danos ou agravos à saúde em razão da omissão do(a) médico(a);

c) no atendimento de complicacoões derivadas de abortamento inseguro, por se tratarem de casos de urgência ${ }^{11}$.

Diante disso, caso haja omissão do médico que resulte em morte ou danos físicos ou psicológicos, este pode ser responsabilizado civil e penalmente por sua conduta omissiva, nos termos do artigo 13, \ $2^{\circ}$ do Código Penal ${ }^{4}$.

Caso o médico entenda que há a possibilidade de exercer a objeção de consciência, deverá garantir a atenção ao abortamento por outro profissional da instituição, conforme estabelece a Norma Técnica do Ministério da Saúde ${ }^{11}$ :

É dever do(da) médico(a) informar à mulher sobre suas condicõoes e direitos e, em caso que caiba a objeção de consciência, garantir a atenção ao abortamento por outro(a) profissional da instituição ou de outro serviço. Não se pode negar o pronto atendimento à mulher em qualquer caso de abortamento, afastando-se, assim, situações de negligência, omissão ou postergação de conduta que violem os direitos bumanos das mulheres ${ }^{11}$.

A mesma norma ainda ratifica e esse entendimento, estabelecendo como obrigação institucional a efetivação dos direitos aos pacientes, inclusive o da interrupção das gestações nos casos permitidos em Lei. ${ }^{11}$

Embora exista o direito do médico à objeção de consciência dentro dos limites acima descritos, é OBRIGACÃO da INSTITUICAOO oferecer aos usuários do SUS todos os seus direitos, inclusive o da interrupção das gestações nos casos previstos em Lei. Qualquer forma de exposição ou negação dos serviços a que tem direito podem ser requeridos e/ ou questionados à luz da justiça. Portanto é importante que os gestores e diretores clínicos estejam preparados para a implementação destes serviços nos hospitais públicos do País ${ }^{11}$.

Neste sentido, Débora Diniz estabelece que "O direito à objeção de consciência não é absoluto, e sua solicitação deve resultar da acomodação entre direitos e valores razoáveis para uma sociedade justa, com danos mínimos para a mulher que busca atendimento médico"15.

A Constituição Federal assegura que ninguém será privado de direitos por motivos de crença religiosa ou de convicção 
filosófica ou política. No entanto, a objeção de consciência não pode ser invocada no sentido de o indivíduo eximirse de obrigação legal, recusando-se a cumprir obrigação alternativa fixada em $l \mathrm{i}^{16}$. Seguindo a normativa constitucional, o Código de Ética Médica ${ }^{12}$ garante o direito à objeção de consciência ao profissional no exercício da medicina, fundamentando-se nos princípios de Respeito à Autonomia e de Liberdade. Dessa forma, o médico pode recusar-se a realizar práticas que vão de encontro aos seus valores morais, mesmo que haja licitude jurídica nelas. Entretanto, se o profissional de saúde estiver diante de uma situação de risco de morte iminente ou de agravos à saúde da mulher, sem que haja um substituto imediato, será obrigado a fazer o procedimento da melhor forma possível respeitando a dignidade da gestante.

O acolhimento das mulheres em processo de abortamento de qualquer natureza deve ser fundamentado no princípio da Dignidade Humana. O Ministério da Saúde elaborou uma Norma Técnica de Atenção Humanizada ao Abortamento $^{1}$ dirigida aos gestores, serviços e profissionais de saúde, objetivando a garantia dos direitos humanos de mulheres e adolescentes no Brasil. A referida Norma Técnica do Ministério da Saúde preconiza que atenção à saúde da mulher deve ser garantida de forma prioritária, havendo respeito à sua dignidade, autonomia e preceitos morais. Segundo ela, a equipe de saúde tem o dever de despir-se de preconceitos, estereótipos e discriminações de qualquer natureza, que possam desumanizar essa atenção, acolhendo a mulher em processo de abortamento ou sob condição legal do procedimento de forma digna, garantindo empenho de meios para sua saúde e bem-estar ${ }^{1}$.

O Princípio da Dignidade da Pessoa Humana, previsto no art. $1^{\circ}$, inciso III da Constituição da República Federativa do Brasil $1^{5}$, é o princípio norteador do sistema normativo brasileiro. O Brasil, como Estado Democrático de Direito, deve ter sempre como fundamento esse Princípio maior, em qualquer circunstância, sendo um substantivo sem significado completamente definido por ser um valor inerente a cada ser humano. Originada do latim (dignitas), a dignidade se relaciona estritamente com a decência, com o decoro, com a probidade e com a integridade ${ }^{18}$. O filósofo alemão Immanuel Kant ${ }^{19}$ traz como imperativo categórico que o ser humano é um fim em si mesmo e, a partir do momento em que esse ser se torna um meio, um instrumento, tem a sua dignidade ferida. Nesse sentido, Ricardo Maurício Freire Soares estabelece o princípio da dignidade da pessoa humana como "pressuposto para a materialização dos direitos fundamentais dos cidadãos, em suas dimensões individuais, sociais e difusas." ${ }^{17}$

Alexandre de Moraes estabelece que a dignidade é um valor espiritual e moral, inerente ao indivíduo, manifestando-se na sua autodeterminação consciente e responsável da sua própria vida, que deve ser assegurado por todo estatuto jurídico $^{16}$. Diante disso, a dignidade da pessoa humana assume um relevo como valor supremo da sociedade, relacionando-se com todos os direitos fundamentais ${ }^{13}$, "implicando, nesse sentido, um complexo de direitos e deveres fundamentais que assegurem à pessoa tanto contra todo e qualquer ato de cunho degradante e desumano, como venham a lhe garantir as condições existenciais mínimas para uma vida saudável [...]"20

Desse modo, toda pessoa deve receber um tratamento consoante com o princípio norteador do ordenamento jurídico brasileiro. É nítido, portanto, que os profissionais de saúde devem estar prontos para o melhor atendimento a alguém que está em processo de abortamento, sendo necessário, ainda, que esses profissionais estejam cientes da licitude do abortamento nos casos previstos por lei.

Preconceitos, estereótipos ou ressentimentos devem ser suprimidos pelo dever do profissional de saúde, que é o tratamento efetivo do ser humano. Quem possui recursos pode encontrar amparo por outras vias, utilizando-se, por exemplo, de viagem com o propósito abortivo. Conforme disposto no artigo "Uma viagem ao Uruguai", quem possui tais recursos pode programar uma viagem a países onde o abortamento é legalizado ou foi descriminalizado, em que a gestante realiza o procedimento com médicos estrangeiros, estando fora da região circunscrita à soberania brasileira para prática do ato $^{20}$. Essa possibilidade descriminaliza o ato praticado, que no Brasil estaria tipificado no art. 124 do Código Penal ${ }^{4}$ com pena cominada de detenção de 1 (um) a 3 (três) anos. Realidade completamente diferente é a da maior parcela da sociedade brasileira que possui menor recurso financeiro. Contudo, apesar dos reforços da elaboração da norma técnica do ministério da saúde para atenção humanizada ao abortamento, existem relatos de maus tratos e de omissão da equipe de saúde por preconceito, razões religiosas ou receio de agressões por grupos ativistas.

Um estudo qualitativo foi realizado com 25 profissionais de saúde que vivenciaram abortamento no seu exercício profissional ${ }^{21}$ em duas maternidades da cidade do Salvador. 
Uma maternidade que oferecia o serviço de abortamento legal e outra, da periferia, que não oferecia o referido serviço, constituíram o cenário para a pesquisa. Os profissionais de saúde que seguiam as normas ministeriais para realização de abortamentos previstos por lei declararam-se vulneráveis à ação de grupos políticos e religiosos. Dentre as situações de vulnerabilidade abordadas, encontra-se o relato de invasão do hospital por um grupo de ativistas espíritas e católicos que tentaram impedir o abortamento em uma adolescente grávida por estupro. Fatos como esses tendem a dificultar os casos de abortamento previstos por lei.

Muitas mulheres, também, perdem seu direito garantido por procrastinação do prazo legal para o procedimento. Relatou-se uma dupla moralidade nos discursos da equipe de saúde. Os profissionais relatavam desconforto ao realizar abortamentos legais e dificuldades em não julgar mulheres que induziram o abortamento. Também foram relatados casos de atitudes punitivas pela equipe de saúde em relação às pacientes que induziram o abortamento, deixandoas sem assistência imediata em processo hemorrágico, inclusive em risco de morte com posterior óbito.

A crítica que se faz, vale dizer, é ao que ocorre efetivamente nesses casos em hospitais. A norma do Ministério da Saúde está seguindo o preceito fundamental da Dignidade da Pessoa Humana, possibilitando até a escolha de técnicas de esvaziamento uterino por abortamento farmacológico, com a substância misoprostol, aspiração manual intrauterina ou curetagem uterina, além de estabelecer o alívio de dores. O que desrespeita o Princípio Constitucional é a eventual atitude de profissionais de saúde que, tratando o paciente que possui o direito da prática do abortamento de forma negligente, fere os preceitos éticos profissionais, bem como o princípio da isonomia, além do princípio da Dignidade da Pessoa Humana. É lamentável que algumas mulheres optem por meios caseiros, sem segurança, higiene ou cuidados pelo fato de saberem que eventualmente serão atendidas por profissionais tomados pelo preconceito. Os estereótipos atingem também as grávidas vítimas do delito de estupro ou as que estão correndo risco de morrer.

\section{CONCLUSÃO|}

A atenção humanizada na assistência à mulher em contexto de abortamento e seus aspectos legais precisam ser amplamente discutidos na sociedade brasileira. A equipe de saúde e todos os cidadãos devem se apropriar do contexto social da prática, e dos aspectos éticos e jurídicos envolvidos na prática do abortamento previsto e não previsto por lei, tendo como alicerce o Princípio da Dignidade da Pessoa Humana.

No presente estudo, foi possível identificar a necessidade de discussão do aborto sob quatro recortes diferentes, quais sejam, o aborto como uma questão de saúde pública, o aborto como uma questão jurídica, o aborto como uma questão religiosa e, por fim, o aborto analisado sob o princípio constitucional da dignidade da pessoa humana.

No âmbito do primeiro recorte em que o aborto foi verificado como uma questão de saúde pública, foram utilizados dados do DATASUS, com a finalidade de investigar em qual setor da sociedade é possível identificar o maior índice da prática abortiva. Após a análise, foi possível concluir que, dentre os 1755 casos de óbito consequentes ao abortamento, 50,6\% correspondiam a mulheres negras/pardas, na faixa etária entre 20-29 anos $(47,3 \%)$, solteiras $(63,6 \%)$, com escolaridade menor que sete anos $(35,5)$ ou ignorada $(38,2)$. Os óbitos foram na grande maioria durante o abortamento (44,8\%) ou período ignorado $(39,4)$ e em ambiente hospitalar $(93,1 \%)$, possibilitando a conclusão de que o abortamento no Brasil incide em mulheres em estado de vulnerabilidade econômica, social e com autonomia reduzida.

É inadmissível que a atenção a mulheres em processo de abortamento sofra interferência de preconceitos e crenças religiosas, ferindo a dignidade da gestante e o princípio da isonomia. As normas de atendimento humanizado ao abortamento devem ser efetivas, possibilitando o melhor tratamento e atenção humanizada à mulher que antes de decidir pela prática insegura, geralmente, passou por sofrimento intenso.

Posteriormente, o aborto foi analisado como uma questão jurídica, tendo sido efetivada a análise dos artigos 124 a 128 do Código Penal, sendo delimitadas as espécies de aborto com suas respectivas penas cominadas, os casos de aumento de pena e os casos em que o aborto é permitido no Brasil, sendo, ainda, verificada a jurisprudência do Supremo Tribunal Federal que, em 2012, por uma votação de oito contra dois Ministros, decidiu na ADPF 54, no sentido da possibilidade da prática abortiva com relação a fetos anencefálicos. 
Ademais, foi possível investigar o aborto como uma questão religiosa, verificando-se, principalmente, a possibilidade da objeção de consciência e limites da recusa pelo médico em realizar o procedimento abortivo, enunciando as principais normativas do Código de Ética Médica que estabelecem a possibilidade da recusa, mas que evidenciam a saúde do paciente como um valor que se sobrepõe à objeção de consciência. Nesse sentido, caso não haja outro profissional para realizar o procedimento, o médico deverá atuar para garantir a efetivação do direito constitucional à saúde, sob pena de responder civil e penalmente por eventual conduta omissiva que resulta em danos ao paciente.

Por fim, foi possível verificar a importância do princípio constitucional da dignidade da pessoa humana em todos os casos em que há a possibilidade da efetivação da prática abortiva. Nesse sentido, todas as gestantes devem ser acolhidas com atenção humanizada pelos profissionais de saúde, nos casos de aborto natural ou nos abortos provocados de forma culposa ou dolosa, inclusive caso haja o "autoaborto", prática ainda tipificada como crime no artigo 124 do Código Penal, mas que não retira o direito da gestante ao atendimento humanizado e o seu direito constitucional à saúde, nos termos do artigo 196 da Constituição Federal.

É certo que o abortamento fora das hipóteses permitidas por lei ainda é crime. Porém, saliente-se que a mulher, independentemente da prática do ato ainda considerado delituoso, é titular do direito à saúde junto ao estado democrático de direito, devendo, portanto, ser assistida em sua saúde. A prática deve ser aplicada tal como a teoria prevista nas normas do Ministério da Saúde. Entretanto, nos casos previstos por lei, embora a mulher possua o direito de praticar o ato de forma segura com equipe especializada para oferecer conforto e procedimento efetivo, nem sempre o ato é realizado em tempo hábil, pelas questões já relatadas.

Assim, os estereótipos formados pelas circunstâncias apresentadas (religião, criminalidade ou moral) devem ser suprimidos com o objetivo de que os tratamentos oferecidos pelos profissionais de saúde estejam conformes o princípio fundamental da Dignidade da Pessoa Humana. A equipe de saúde deve estar preparada, com neutralidade axiológica e sem preconceito de qualquer ordem, atendendo às gestantes de forma humanizada. Desse modo, as normativas do Ministério da Saúde e o princípio da dignidade da pessoa humana poderão ser efetivados.

\section{REFERÊNCIAS |}

1. Brasil. Ministério da Saúde. Atenção humanizada ao abortamento: norma técnica [Internet]. 2. ed. Brasília: Ministério da Saúde; 2011 [acesso em 22 mar 2019]. Disponível em: URL: <http://bvsms.saude.gov.br/bvs/ publicacoes/atencao_humanizada_abortamento.pdf $>$.

2. Guttmacher Institute [Internet]. International abortion [acesso em 22 mar 2019]. Disponível em: URL: <http://www.guttmacher.org/media/presskits/abortionWW/graphics.html>.

3. Adesse L, Monteiro MFG. Magnitude do aborto no Brasil: aspectos epidemiológicos e sócio-culturais [Internet]. Brasília: IPAS; 2007 [acesso em 22 mar 2019]. Disponível em: URL: <http://bvsms.saude.gov.br/bvs/ publicacoes/magnitude_aborto_brasil.pdf $>$.

4. Brasil. Decreto-lei no. 2848, de 7 de dezembro de 1940. Código Penal. Diário Oficial da União 31 dez 1940.

5. Brasil. Constituição (1988). Constituição da República Federativa do Brasil. Brasília: Senado Federal; 1988.

6. Gustin MBS, Dias MTF. (Re)pensando a pesquisa jurídica: teoria e prática. 4. ed.Belo Horizonte: Del Rey; 2013.

7. Diniz D. Aborto e saúde pública: 20 anos de pesquisas no Brasil Brasília: UNB; 2008.

8. Diniz D, Medeiros M. Aborto no Brasil: uma pesquisa domiciliar com técnica de urna. Ciênc Saúde Coletiva. 2010; 15(supl. 1):959-66.

9. Brasil. Ministério da Saúde [Internet]. Informações de saúde: estatísticas vitais [acesso em 22 mar 2019]. Disponível em: <http://www2.datasus.gov.br/DATASUS/index. php?area $=0205>$.

10. Pereira VN, Oliveira FA, Gomes NP, Couto TM, Paixão GPN. Abortamento induzido: vivência de mulheres baianas. Saúde Soc. 2012; 21(4):1056-62.

11. Brasil. Ministério da Saúde. Prevenção e tratamento dos agravos resultantes da violência sexual contra mulheres e adolescentes: norma técnica. 2. ed. Brasília: Ministério da Saúde; 2005. 
12. Conselho Federal de Medicina (Brasil). Resolução $n^{\circ}$. 1931, de 24 de setembro de 2009. Aprova o Código de Ética Médica [Internet]. Diário Oficial da União 24 set 2009 [acesso em 22 mar 2019]; Seção 1(183). Disponível em: URL: <http://www.portalmedico.org.br/novocodigo/integra.asp $>$.

13. Cunha Junior D. Curso de direito constitucional. 11. ed. Salvador: Juspodivm; 2017.

14. Greco R. Curso de direito penal. 10. ed. Niterói: Impetus; 2013. p. 228-53.

15. Diniz D. Objeção de consciência e aborto: direitos e deveres dos médicos na saúde pública. Rev Saúde Pública. 2011; 45(5):981-5

16. Moraes A. Direitos humanos fundamentais: teoria geral, comentários aos arts. $1^{\circ}$ a $5^{\circ}$ da Constituição da República Federativa do Brasil, doutrina e jurisprudência. 4. ed. São Paulo: Atlas; 2002.

17. Soares RMF. O princípio constitucional da dignidade da pessoa humana: em busca do direito justo. São Paulo: Saraiva; 2010. p. 18.

18. Sarlet IW. Dignidade da pessoa humana e direitos fundamentais na Constituição Federal de 1988. 2. ed. Porto Alegre: Livraria do Advogado; 2002.

19. Kant I. A metafísica dos costumes. Bauru: Edipro; 2003.

20. Diniz D. Aborto: uma viagem ao Uruguai [Internet]. Correio Braziliense 2012 out 23 [acesso em 22 mar 2019]; p. 19. Disponível em: URL: <http://www2. senado.leg.br/bdsf/bitstream/handle/id/56643/noticia. htm? sequence $=1>$.

21. Zordo S. Representações e experiências sobre aborto legal e ilegal dos ginecologistas-obstetras trabalhando em dois hospitais maternidade de Salvador da Bahia. Ciênc Saúde Coletiva. 2012; 17(7):1745-54.
Correspondência para/ Reprint request to:

\section{Liliane Lins-Kusterer}

Faculdade de Medicina da Babia, SN, Canela, Salvador/BA, Brasil

CEP: 40110-100

Tel.: (71) 3283-5577

E-mail:lkusterer@gmail.com

Recebido em: 11/03/2019

Aceito em: 02/06/2019 